\title{
Rzadka wrodzona wada zastawki aortalnej
}

\author{
Rare congenital defect of aortic valve
}

\author{
Katarzyna Stopyra-Pach ${ }^{1}$, Małgorzata Konieczyńska ${ }^{1}$, Bartosz Laskowicz², \\ Robert Banyś ${ }^{2}$, Małgorzata Urbańczyk-Zawadzka² \\ ${ }^{1}$ Oddział Szybkiej Diagnostyki Krakowskiego Szpitala Specjalistycznego im. Jana Pawła II \\ ${ }^{2}$ Zakład Radiologii i Diagnostyki Obrazowej Krakowskiego Szpitala Specjalistycznego im. Jana Pawła II
}

\section{Streszczenie}

Czteropłatkowa zastawka aortalna (QAV) należy do rzadkich wad wrodzonych serca. Zwykle jest to izolowana wada serca. Zależnie od wielkości płatków zastawki wyróżnia się 7 anatomicznych wariantów QAV. Może ona predysponować do rozwoju zaburzeń funkcjonowania, najczęściej niedomykalności. Postępowanie terapeutyczne u pacjentów z QAV jest determinowane głównie stopniem dysfunkcji zastawki. W pracy przedstawiono przypadek pacjentki, u której przypadkowo podczas diagnostyki nietypowych dolegliwości bólowych w klatce piersiowej wykryto czteropłatkową zastawkę aortalną.

Słowa kluczowe: wada wrodzona zastawki aortalnej, zastawka czteropłatkowa, nietypowy ból w klatce piersiowej, angio-CT, ECHO

Folia Cardiologica 2017; 12, 6: 605-608

\section{Wstęp}

Czteropłatkowa zastawka aortalna (QAV, quadricuspid aortic valve) jest rzadką wrodzoną wada zastawkową serca. Częstość występowania tej wrodzonej anomalii szacuje się na 0,0065-0,013\% (na podstawie badań autopsyjnych i rejestrów badań echokardiograficznych) [1-3]. W niniejszym artykule przedstawiono przypadek pacjentki, u której przypadkowo - podczas diagnostyki nietypowych dolegliwości bólowych w klatce piersiowej - wykryto QAV.

\section{Opis przypadku}

Chora w wieku 68 lat została skierowana do szpitala specjalistycznego w celu poszerzenia diagnostyki kardiologicznej. W wywiadzie podawała nietypowe dolegliwości bólowe w klatce piersiowej. U pacjentki występowały schorzenia współistniejące: nadciśnienie tętnicze, hipercholesterolemia, nieprawidłowa glikemia na czczo, nadwaga, zmiany zwyrodnieniowe stawów kręgosłupa, stan po cholecystek- tomii z powodu kamicy pęcherzyka żółciowego. W badaniu przedmiotowym stwierdzono wyrównany stan układów sercowo-naczyniowego i oddychania. Wykonana ambulatoryjnie próba wysiłkowa okazała się niediagnostyczna z powodu nieosiągnięcia tętna submaksymalnego. W przezklatkowym badaniu echokardiograficznym stwierdzono nieznacznie poszerzony lewy przedsionek (w projekcji przymostkowej w osi długiej wymiar lewego przedsionka $41 \mathrm{~mm}$ ), przy prawidłowej wielkości pozostałych jam serca oraz prawidłowe grubość i funkcję skurczową miokardium (globalną i odcinkową, frakcja wyrzutowa lewej komory [LVEF, left ventricular ejection fraction] $=60 \%$ ), przy łagodnie zaburzonej funkcji rozkurczowej (iloraz maksymalnej prędkości fali wczesnego napływu mitralnego do maksymalnej prędkości w czasie skurczu przedsionka [E/A] 0,8; czas deceleracji fali wczesnego napływu mitralnego [DT, deceleration time] 229 ms; iloraz maksymalnej prędkości fali wczesnego napływu mitralnego do wczesnorozkurczowej maksymalnej prędkości ruchu miokardium [E/E'] 10). Uwidoczniono QAV z nieco pogrubiałymi brzegami płatków (ryc. 1) i łagodną

Adres do korespondencji: dr n. med. Katarzyna Stopyra-Pach, Oddział Szybkiej Diagnostyki, Krakowski Szpital Specjalistyczny im. Jana Pawła II, ul. Prądnicka 80, 31-202 Kraków, e-mail: stopyrapach@gmail.com 


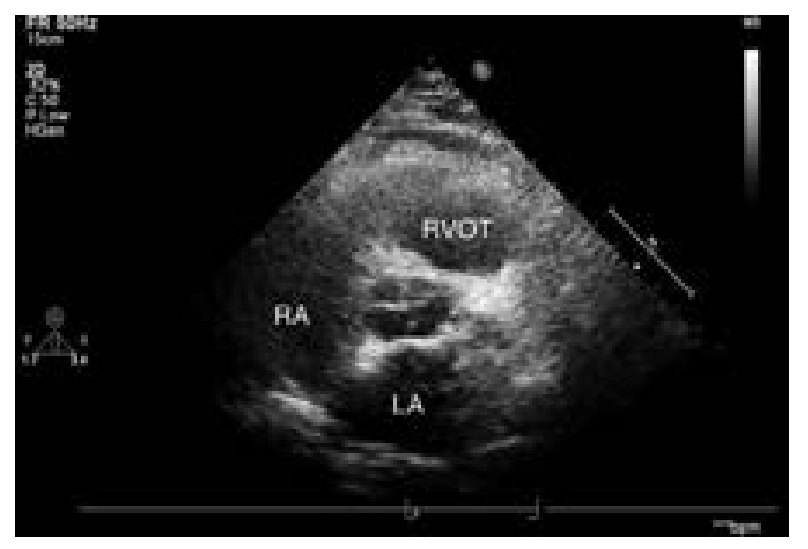

Rycina 1. Przezklatkowe badanie echokardiograficzne, projekcja w osi krótkiej na poziomie zastawki aortalnej - widoczna czteropłatkowa zastawka aortalna w pozycji zamkniętej; RVOT (right ventricle outflow tract) - droga odpływu prawej komory; RA (right atrium) - prawy przedsionek; LA (left atrium) - lewy przedsionek

niedomykalnością (ryc. 2), aortę wstępującą i łuk aortalny prawidłowej szerokości (odpowiednio $32 \mathrm{~mm}$ i $26 \mathrm{~mm}$ ). Dodatkowo stwierdzono współistniejącą niedomykalność zastawki mitralnej w stopniu umiarkowanym. Diagnostykę obrazową poszerzono o angiografię tomografii komputerowej (angio-CT, angiography computed tomography). W badaniu tym zobrazowano tętnice wieńcowe bez istotnych przewężeń oraz powierzchowny most mięśniowy nad gałęzią międzykomorową przednią (bez cech przewężenia naczynia w skurczu), który mógł tłumaczyć zgłaszane przez pacjentkę dolegliwości bólowe w klatce piersiowej. Dodatkowo uwidoczniono zastawkę aortalną z wrodzoną anomalią anatomiczną w postaci czteropłatkowej zastawki (ryc. 3). Ze względu na brak istotnej dysfunkcji zastawki aortalnej pacjentkę zakwalifikowano do grupy obserwacyjnej z okre- sową kontrolą echokardiograficzną oraz do kontynuacji farmakoterapii chorób współistniejących.

\section{Omówienie}

Czteropłatkowa zastawka aortalna jest rzadką, zwykle izolowaną wadą serca, ale w nielicznych przypadkach może towarzyszyć innym wrodzonym nieprawidłowościom sercowo-naczyniowym [1, 4, 5]. Po raz pierwszy rozpoznał ją Balington w 1862 roku (cytowany w [6]). Zależnie od wielkości poszczególnych płatków zastawki wyróżnia się 7 wariantów anatomicznych QAV (typy A-G, ryc. 4), spośród których najczęstszymi wariantami są typ A (wszystkie płatki jednakowej wielkości) i typ B (jeden płatek mniejszy, pozostałe równej wielkości) [1, 7]. Czteropłatkowa zastawka aortalna może predysponować do rozwoju zaburzeń jej funkcjonowania - najczęściej niedomykalności, a także do nieprawidłowości w obrębie aorty. Tsang i wsp. [1], badając echokardiograficzną bazę danych z Mayo Clinic z lat 1975-2014, spośród 431505 pacjentów wyodrębnili grupę 52 osób z QAV. W swoim badaniu stwierdzili, że najczęstszą współistniejącą nieprawidłowością u pacjentów z QAV było poszerzenie aorty (29\% pacjentów), a najczęstszym zaburzeniem funkcji QAV była jej niedomykalność (niedomykalność w stopniu przynajmniej umiarkowanym dotyczyła 26\% pacjentów z QAV). Zwężenie QAV obserwowali jedynie u 8\% pacjentów, przy czym była to łagodna wada. Badacze ci nie stwierdzili związku między typem zastawki (typy A-G) a stopniem nasilenia jej niedomykalności [1]. Rokowanie pacjentów z QAV z reguły jest dobre [1]. Postępowanie terapeutyczne u tych chorych jest determinowane głównie stopniem dysfunkcji zastawki [8]. Izolowana niedomykalność w stopniu łagodnym bądź umiarkowanym wymaga okresowej kontroli echokardiograficznej. Postępowanie
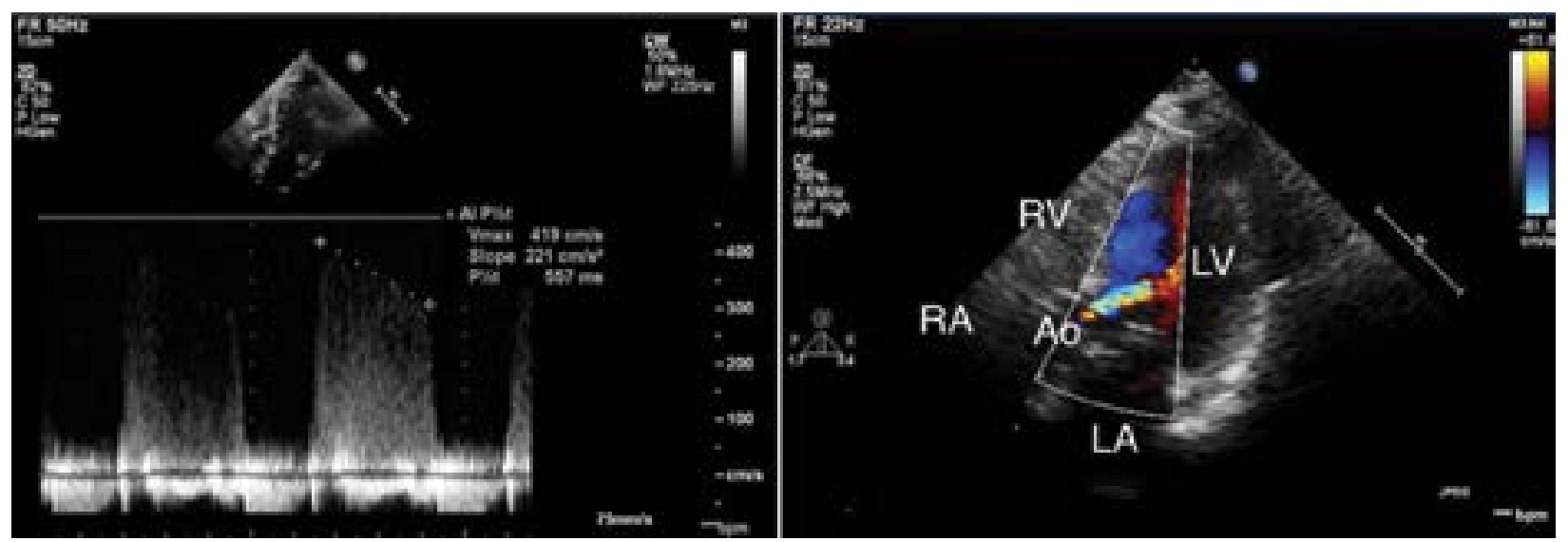

Rycina 2A, B. Przezklatkowe badanie echokardiograficzne, projekcja koniuszkowa pięciojamowa - widoczna fala zwrotna przez zastawkę aortalną: A. Badanie metodą Dopplera fali ciągłej; B. Badanie kolorowym doplerem; RA (right atrium) - prawy przedsionek; LA (left atrium) - lewy przedsionek; RV (right ventricle) - prawa komora; LV (left ventricle) - lewa komora; Ao - aorta wstępująca 

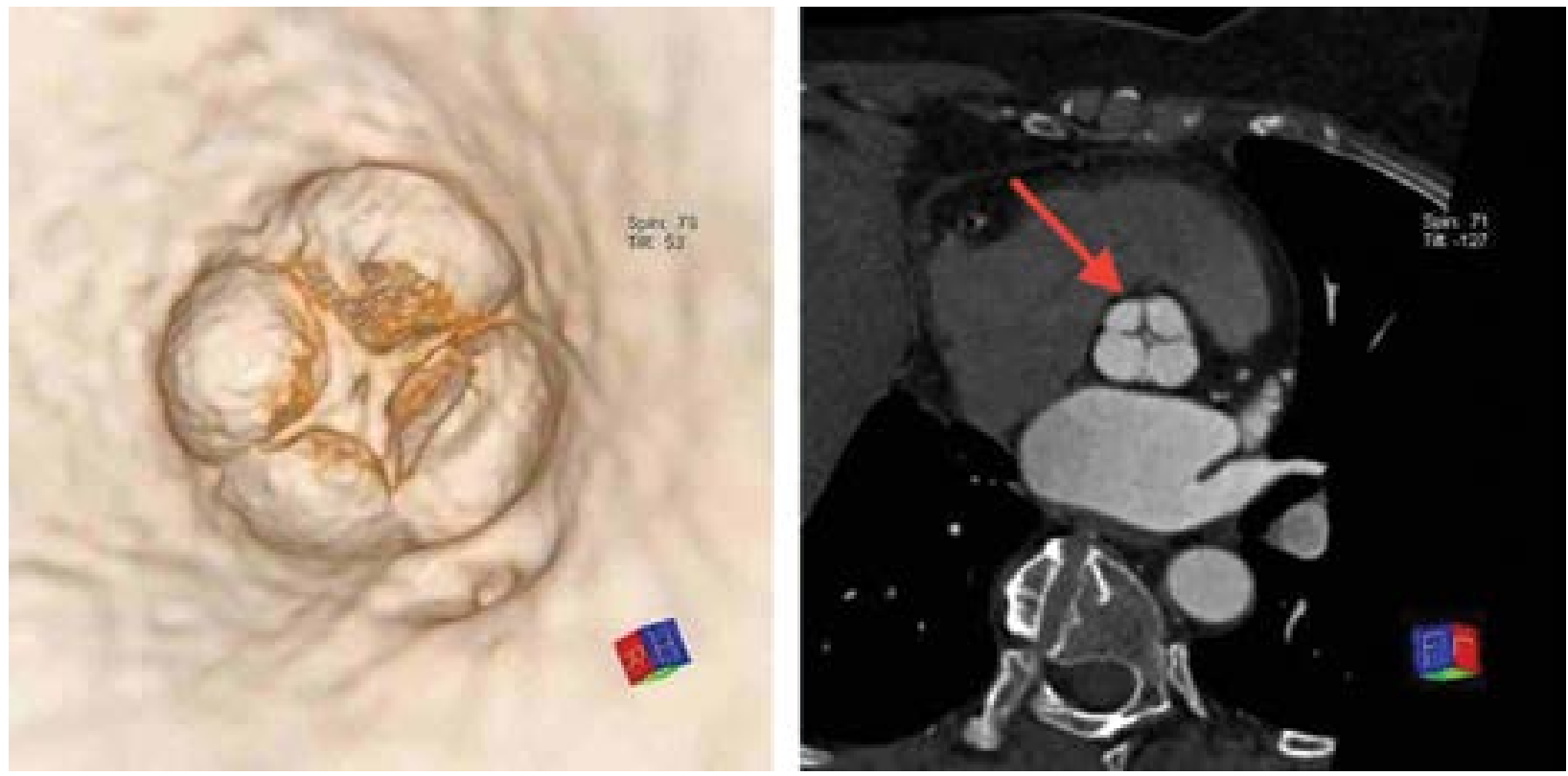

Rycina 3A, B. Angiografia tomografii komputerowej serca: A. Czteropłatkowa zastawka aortalna (QAV, quadricuspid aortic valve) - wirtualna endoskopia; B. Rekonstrukcja wielopłaszczyznowa (MPR, mulitplanar reformation) (czerwoną strzałką oznaczono QAV)

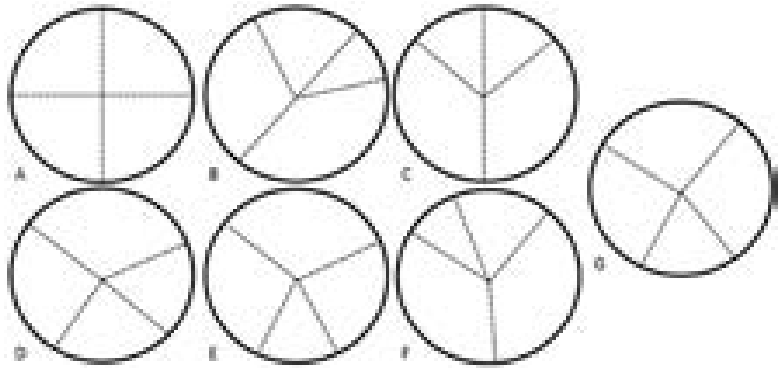

Rycina 4. Warianty anatomiczne czteropłatkowej zastawki aortalnej (typy A-G) (ryc. własna na podstawie [6, 7])

w przypadku wady istotnej hemodynamicznie jest identyczne jak w przypadku niedomykalności o odmiennej etiologii $[9,10]$.

\section{Podsumowanie}

Przypadek QAV opisywany w niniejszym artykule odpowiada typowi F zastawki (dwa równe płatki większe i dwa nierówne płatki mniejsze), co potwierdzono w badaniu angio-CT. W badaniu echokardiograficznym stwierdzono jej łagodna niedomykalność przy prawidłowej szerokości aorty. Biorąc pod uwage całość obrazu klinicznego, opisywaną pacjentkę z QAV zakwalifikowano do grupy obserwacyjnej z okresową kontrolą echokardiograficzną wady zastawki aortalnej i mitralnej, kontynuacji farmakoterapii chorób współistniejących i modyfikacji czynników ryzyka miażdżycy.

\section{Konflikt interesów}

Autorzy nie zgłaszają konfliktu interesów.

\section{Abstract}

Quadricuspid aortic valve (QAV) is a rare congenital heart defect. Most frequently it is isolated defect. There are 7 anatomical variants of QAV depending on cuspids size. QAV may lead to malfunction of the valve, most frequently to aortic valve insufficiency. Management of patients with QAV is determined mainly by the severity of dysfunction. This paper includes description of a female patient, diagnosed because of atypical chest pain, in whom quadricuspid aortic valve was revealed.

Key words: congenital defect of aortic valve, quadricuspid valve, atypical chest pain, angio-CT, heart ECHO

Folia Cardiologica 2017; 12, 6: 605-608 


\section{Piśmiennictwo}

1. Tsang MYC, Abudiab MM, Ammash NM, et al. Quadricuspid Aortic Valve: Characteristics, Associated Structural Cardiovascular Abnormalities, and Clinical Outcomes. Circulation. 2016; 133(3): 312-319, doi: 10.1161/CIRCULATIONAHA.115.017743, indexed in Pubmed: 26635401.

2. Simonds JP. Congenital malformations of the aortic and pulmonary valves. Am J Med Sci. 1923; 166(4): 584-595, doi: 10.1097/ /00000441-192310000-00013.

3. Feldman BJ, Khandheria BK, Warnes CA, et al. Incidence, description and functional assessment of isolated quadricuspid aortic valves. Am J Cardiol. 1990; 65(13): 937-938, indexed in Pubmed: 2181849.

4. Sousa L, Pinto F, Nogueira G, et al. Quadricuspid aortic valve and atrial septal defect. Rev Port Cardiol. 2001; 20(3): 329-330, indexed in Pubmed: 11417316.
5. Janssens U, Klues HG, Hanrath P. Congenital quadricuspid aortic valve anomaly associated with hypertrophic non-obstructive cardiomyopathy: a case report and review of the literature. Heart. 1997; 78(1): 83-87, indexed in Pubmed: 9290407.

6. Jedliński I, Jamrozek-Jedlińska M, Bugajski P, et al. Czeropłatkowa zastawka aortalna. Kardiol Pol. 2011; 69: 1084-1086.

7. Hurwitz LE, Roberts WC. Quadricuspid semilunar valve. Am J Cardiol. 1973; 31(5): 623-626, indexed in Pubmed: 4698133.

8. Bonde P, Sachithanandan A, McClements B, et al. Quadricuspid aortic valve: a rare cause of aortic insufficiency. J Heart Valve Dis. 2002; 11(4): 506-508, indexed in Pubmed: 12150298.

9. Tutarel 0 . The quadricuspid aortic valve: a comprehensive review. J Heart Valve Dis. 2004; 13(4):534-537, indexed in Pubmed: 15311857.

10. Wytyczne dotyczące postępowania w zastawkowych wadach serca na 2012 rok. Kardiol Pol. 2012; 70(Suppl VII): S319-S372. 


\section{Komentarz}
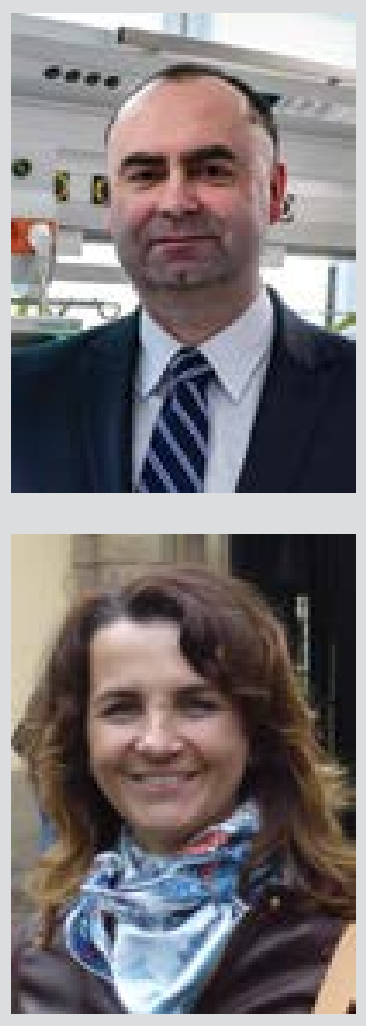

dr hab. n. med. Ireneusz Haponiuk, prof. nadzw., ${ }^{1,2}$ dr n. med. Katarzyna Gierat-Haponiuk ${ }^{2,3}$

${ }^{1}$ Oddział Kardiochirurgii Dziecięcej Szpitala im. św. Wojciecha w Gdańsku-Zaspie

${ }^{2}$ Katedra Fizjoterapii Wydziału Rehabilitacji i Kinezjologii

Akademii Wychowania Fizycznego i Sportu im. Jędrzeja Śniadeckiego w Gdańsku

${ }^{3}$ Klinika Rehabilitacji Gdańskiego Uniwersytetu Medycznego

Zastawka aortalna jest strukturą trójpłatkową, osadzoną w pierścieniu, od którego rozpoczyna się początkowy odcinek tętnicy głównej zwany opuszką aorty. Odpowiednie płatki tworzą trzy zatoki Valsalvy, tj. lewo- i prawo-wieńcową, od których biorą początek tętnice wieńcowe - prawa i lewa, oraz bezwieńcową. Prawidłowo funkcjonujące płatki zapewniają swobodny wypływ skurczowy z lewej komory, bez niedomykalności zastawki w fazie rozkurczu. Najczęstszą wrodzoną anomalią zastawki aortalnej jest jej wariant dwupłatkowy, który może występować jako anomalia izolowana lub też towarzyszyć innym wrodzonym wadom serca. Wśród wad wrodzonych lewego ujścia tętniczego rzadziej opisywane są jednopłatkowe zastawki aortalne, wymagające zazwyczaj pilnego leczenia interwencyjnego już we wczesnym okresie życia noworodka [1], a także formy wielopłatkowe, najczęściej diagnozowane incydentalnie ze względu na łagodną manifestację kliniczną [2]. We wszystkich postaciach wad wrodzonych zastawki aortalnej podkreśla się zagrożenie związane z potencjalną dysfunkcją zastawki, oraz wynikającą z tego potrzebę regularnej kontroli kardiologicznej, i konieczność profilaktyki infekcyjnego zapalenia wsierdzia (IZW) u pacjentów ze zdefiniowaną wadą, niezależnie od często skąpoobjawowego przebiegu [3]. Dla przykładu prezentujemy obraz echokardiograficzny dwupłatkowej zastawki aortalnej z wadą pierścienia aortalnego w zakresie odpowiadającym anatomicznej pozycji płatka bezwieńcowego, powikłanej ostrym IZW z wytworzeniem ropnia okołopierścieniowego. Chory w wieku 9 lat wymagał pilnej operacji usunięcia ropnia z zamknięciem jego jamy oraz wszczepienia mechanicznej protezy w trakcie intensywnej antybiotykoterapii IZW (ryc. 1).

Autorzy przedstawili przypadek rzadko spotykanej wady serca, jaką jest czteropłatkowa zastawka aortalna (QAV, quadricuspid aortic valve), której występowanie na podstawie badań echokardiograficznych i pośmiertnych ocenia się

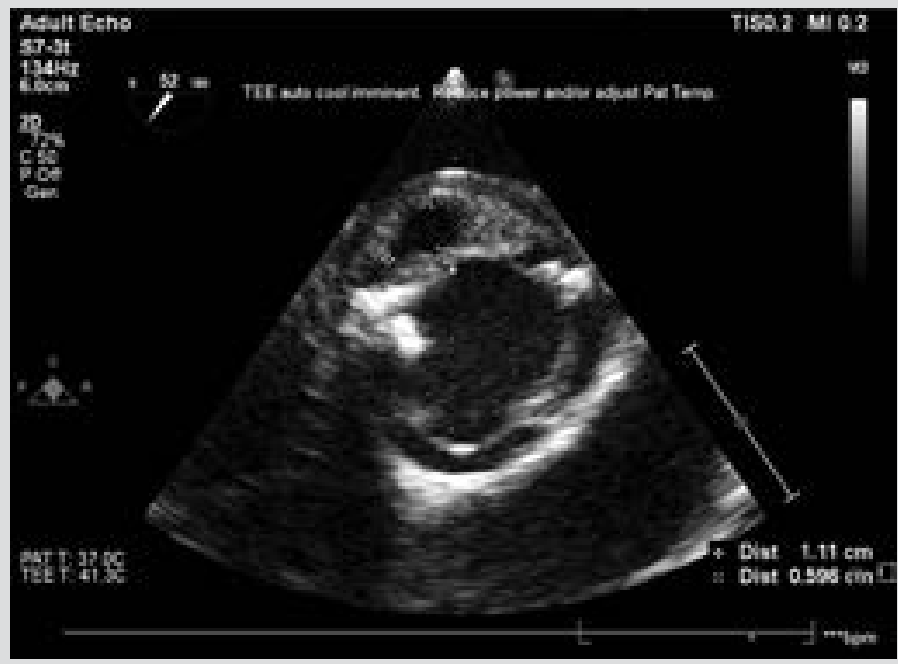

Rycina 1. Obraz echokardiografii przezprzełykowej (TEE, transesophageal echocardiography) dwupłatkowej zastawki aortalnej z wadą pierścienia aortalnego w zakresie odpowiadającym anatomicznej pozycji płatka bezwieńcowego, powikłanej ostrym infekcyjnym zapaleniem wsierdzia (IZW) z degeneracją obu płatków iwytworzeniem ropnia okołopierścieniowego, z istotną dysfunkcją skurczowo-rozkurczową (materiał własny) 
na poniżej 0,1\% chorych. Czteropłatkowa zastawka aortalna występuje w siedmiu wariantach anatomicznych (typy A-G), które wyróżniono na podstawie różnej budowy i wielkości jej płatków [4, 5]. Opisywaną w pracy morfologię QAV zaliczono do jednego z częściej występujących wariantów tej wady - typu A, w którym wszystkie płatki są jednakowej wielkości [5]. W tej formie ryzyko dysfunkcji zastawki wydaje się najniższe.

Autorzy podkreślają wartość badania echokardiograficznego w rozpoznaniu tej wady serca. W tym badaniu ocenia się niedomykalność QAV, co może być podstawowym problemem klinicznym w tej wadzie, nasilającym się z wiekiem chorego. Łagodna lub umiarkowana wymaga stałej kontroli (jak w przypadku omawianej pacjentki), zaś istotna stanowi wskazanie do leczenia operacyjnego (plastyka zastawki lub wszczepienie protezy) albo interwencyjnego, z przezskórnym lub hybrydowym wszczepieniem stentowanej rozprężalnej zastawki aortalnej (TAVI, transcatheter aortic valve implantation) [6]. Autorzy słusznie podkreślili konieczność wnikliwej oceny mogącego towarzyszyć omawianej wadzie zastawkowej poszerzenia aorty wstępującej, którego szczęśliwie nie stwierdzono u opisywanej pacjentki.

W artykule zwrócono uwagę na rolę badania angiografii tomografii komputerowej (angio-CT, angiography computed tomography), które umożliwiło potwierdzenie anatomicznego typu A wady zastawki aortalnej o morfologii QAV. Najbardziej istotne dla dalszej terapii okazało się w naszym przekonaniu wykluczenie przewężeń tętnic wieńcowych i ujawnienie mostu mięśniowego nad gałęzią międzykomorową przednią, co prawdopodobnie mogło być główną przyczyną zgłaszanych dolegliwości w postaci bólu w klatce piersiowej.

\section{Piśmiennictwo}

1. Przybylski R, Borzymowski J, Skalski JH. Chirurgia wad lewego ujścia tętniczego. In: Skalski J, Religa Z. ed. Kardiochirurgia dziecięca. Wyd. I. Wydawnictwo „Śląsk”, Katowice 2003: 113-135.

2. Feldman BJ, Khandheria BK, Warnes CA, et al. Incidence, description and functional assessment of isolated quadricuspid aortic valves. Am J Cardiol. 1990; 65(13): 937-938, indexed in Pubmed: 2181849.

3. Wytyczne dotyczące postępowania w zastawkowych wadach serca na 2012 rok. Wspólna grupa robocza ESC i EACTS. Kardiol Pol. Kardiol Pol. 2012; 372(Suppl VII): S319-S372.
4. Jedliński I, Jamrozek-Jedlińska M, Bugajski P, et al. Czeropłatkowa zastawka aortalna. Kardiol Pol. 2011; 69: 1084-1086.

5. Stopyra-Pach K, Konieczyńska M, Laskowicz B, et al. Rzadka wrodzona wada zastawki aortalnej. Folia Cardiol. 2017; 6(12): 605-608, doi: 10.5603/FC.2017.0115.

6. Kochman J, Kołtowski Ł, Huczek Z, et al. Porównanie dostępu przezskórnego z dostępem chirurgicznym u pacjentów poddawanych przezcewnikowej implantacji zastawki aortalnej od tętnicy udowej - wyniki wieloośrodkowego rejestru TAVI. Kardiol Pol. 2017, doi: 10.5603/kp.a2017.0205. 